\title{
DIREITO À EDUCAÇÃO E SUA JUDICIALIZAÇÃO: ASPECTOS FUNDAMENTAIS
}

\author{
THE RIGHT TO EDUCATION AND ITS JUDICIALIZATION: FUNDAMENTAL ASPECTS
}

\author{
(D) Marcelo Costa Ribeiro \\ Mestre em Educação, Universidade do Vale do Sapucaí - UNIVÁS \\ Pouso Alegre, Minas Gerais, Brasil \\ costaribeiro.marcelo@gmail.com \\ Deide Pena \\ Doutora em Educação, Pontifícia Universidade Católica de São Paulo - PUC/SP \\ Pouso Alegre, Minas Gerais, Brasil \\ neideunivas@gmail.com \\ (D) Ronaldo Júlio Baganha \\ Doutor em Ciências do Movimento Humano, Universidade Metodista de Piracicaba - UNIMEP \\ Piracicaba, SP, Brasil. \\ ronaldobaganha@yahoo.com.br
}

\begin{abstract}
Resumo: O artigo discute a judicialização do direito à educação no Brasil e seus aspectos social, jurídico e político-administrativo. Justifica-se por ser a educação um dever, constitucionalmente reconhecido pelo Poder Público, representado pelo Estado e os entes federados ante a responsabilidade de prover a sociedade de recursos necessários para garantir o direito à educação, conforme Constituição Federal de 1988, art. 205. Observa-se que os direitos educacionais são amplamente garantidos na legislação brasileira, mas nem sempre são respeitados por aqueles que têm o dever de garantir políticas públicas consoantes a esse fim. O objetivo deste artigo é evidenciar a importância da "judicialização" como um conjunto de procedimentos jurídicos cujo propósito é garantir o direito subjetivo público do cidadão, com vistas a exigir o cumprimento do dever do Poder Público em qualquer instância federativa. Quando, em algum aspecto, a efetivação desse direito não é atendida pelas políticas públicas, a judicialização pode ser um meio ou uma estratégia pela via jurídica, capaz de compelir o poder público em questão a cumprir seu dever estatuído na Constituição Federal quanto à garantia do direito à educação. A pesquisa teve caráter exploratório, abordagem qualitativa, com finalidade explicativa, e sua realização se deu por meio da revisão documental, articulando aspectos jurídicos, via atos normativos, políticas e legislação vigentes, além do estado da arte sobre o tema "judicialização", realizada por meio de uma Revisão Sistemática (RS), considerando o percurso histórico da educação no Brasil.
\end{abstract}

Palavras-chave: Direito. Educação. Judicialização. Políticas públicas.

Abstract: The article discusses the judicialization of the right to education in Brazil and its social, legal, and political-administrative aspects. It is justified because education is a duty, constitutionally recognized by the Public Power, represented by the State and the federated entities before the responsibility of providing society with the necessary resources to guarantee the right to education, according to the Federal Constitution of 1988, art. 205. We could note that educational rights are largely guaranteed in Brazilian legislation but are not always respected by those who must ensure public policies under this purpose. The purpose of this article is to highlight the importance of "judicialization" as a set of legal procedures, the purpose of which is to guarantee the citizen's subjective public right aiming to demand that the Public Power fulfils its duties in any federative instance. When, in some aspect, the realization of this right is not met by public policies, judicialization can be a means or a strategy through legal means, capable of compelling the public power in question to fulfil its duty stipulated in the Federal Constitution regarding guaranteeing the right to education. The research had an exploratory character, qualitative approach, and explanatory purpose. It was carried out through documentary review, articulating legal aspects through current normative acts, policies, and legislation, besides state of the art on the theme "judicialization", carried out by through a Systematic Review (RS) that considers the historical path of education in Brazil.

Keywords: Right to education. Judicialization. Public policies.

\section{Para citar - ABNT NBR 6023:2018}

RIBEIRO, Marcelo Costa; PENA, Neide; BAGANHA, Ronaldo Júlio. Direito à educação e sua judicialização: aspectos fundamentais. Cadernos de Pós-graduação, São Paulo, v. 19, n. 2, p. 159-172, jul./dez. 2020. Disponível em: https://doi.org/10.5585/cpg.v19n2.18112. 


\section{Introdução}

Abordar o tema judicialização do direito à educação, no artigo que ora se apresenta, significou mergulhar em um conjunto de direitos sociais que estão no entorno das políticas educacionais, uma vez que a educação se configura um direito de todos, reconhecido há mais de 70 (setenta) anos pela Declaração Universal dos Direitos do Homem. Proclamada pela Organização das Nações Unidas, em seu artigo 26, a referida Declaração estabelece que toda pessoa tem direito à educação e, esta, por sua vez, deve ser gratuita e obrigatória, ao menos a correspondente ao ensino elementar fundamental. No Brasil, a Constituição Federal de 1988 consolida este direito no art. 205, em especial, no qual atribui ao Estado e à família o dever de garantir o exercício desse direito com a colaboração da sociedade civil (BRASIL, 1988).

O ordenamento jurídico vigente no Brasil reconhece a educação como "um direito social e fundamental" do ser humano e o concebe como um direito público subjetivo para seu exercício em sociedade e, para torná-lo efetivo, fez-se necessário instituir mecanismos processuais (administrativos e judiciais) capazes de exigir do Poder Público o cumprimento deste direito em suas diversas situações. Nesse contexto, quando em algum aspecto o direito à educação não é atendido pelas políticas públicas, é possível recorrer à judicialização como alternativa, desde que esgotados os recursos administrativos para o cumprimento deste direito.

Neste artigo, objetiva-se evidenciar que a “judicialização” é um conjunto de procedimentos jurídicos cujo propósito é garantir o direito subjetivo público do cidadão com vistas a exigir o cumprimento do dever do Estado em qualquer instância federativa, ou seja, no âmbito Federal, Estadual, Municipal ou Distrito Federal. Como Poder Público, os entes federados têm o dever de garantir a execução plena da proposta de educação consoante às diretrizes traçadas na agenda de implantação e implementação das políticas públicas com esse fim, haja vista que os direitos educacionais são amplamente garantidos na legislação brasileira (CURY, 1998; 2002), mas nem sempre são respeitados.

Como a judicialização no âmbito educacional se trata de algo que pode ser considerado de certa forma novo - e até mesmo desconhecido - por alguns profissionais dessa área e pelos próprios cidadãos, destaca-se a relevância que o tema apresenta como questão de pesquisa e como política pública, especialmente para área educacional, além do seu caráter pedagógico na sociedade constitucionalmente democrática. Esse lado pedagógico se refere à necessidade de levar ao conhecimento dos profissionais da educação o que é a judicialização juridicamente, e como este recurso específico pode ser utilizado quando, em algum aspecto, o direito à educação não está sendo atendido, portanto, considera-se neste texto, que o processo de judicialização pode ser tratado como um ato pedagógico e político de formação para a cidadania. 
A pesquisa que deu origem a este artigo é de abordagem qualitativa, caráter exploratório e com a finalidade explicativa. Foi realizada por meio da revisão documental, articulando aspectos jurídicos, via atos normativos, políticas e legislação da área educacional vigentes, considerando o percurso histórico da educação, como direito, no Brasil. Levantou-se o estado da arte sobre o tema “judicialização”, relacionado ao direito à educação, por meio de uma Revisão Sistemática (RS), desenvolvida para avaliar criticamente evidências acerca de um determinado tópico (BIOLCHINI et al., 2007). Por ser uma metodologia de rigorosa confiabilidade, reconhecida no universo da pesquisa, possibilitou realizar um levantamento bibliográfico preciso e adequado, com o propósito de aferir o estado da arte no domínio explorado (KITCHENHAM, 2004).

$\mathrm{O}$ artigo se destina aos gestores da educação, aos docentes e às instituições de representatividade coletiva de proteção a esse direito. Nesse sentido, a repercussão desse tema na área educacional pode significar um dos meios capazes de garantir e proteger o direito à educação, compelindo o Poder Executivo e o Legislativo, em qualquer esfera de Governo, a cumprirem o que thes cabe no que se refere à efetivação desse direito, conforme prescrito na Constituição Federal de 1988 e reconhecido em outros atos normativos, como a LDB No 9394/1996, Plano Nacional de Educação, Estatuto da Criança e do Adolescente (ECA) e outros.

\section{Fundamentação teórica: explorando o reconhecimento do direito à educação}

O período entre a década de 90 do século anterior até a atualidade trouxe alterações significativas ao conjunto das políticas educativas para a educação, principalmente com a publicação da Lei de Diretrizes e Bases da Educação Nacional - LDBEN (BRASIL, 1996). Tais mudanças podem ser inseridas no contexto de reformas e políticas que se propagaram em âmbito global em face de relações sociais, políticas e econômicas que, em certa medida, estão relacionadas ao novo mundo produtivo (FAVARO; TUMOLO, 2016, p. 559), mas com acentuadas repercussões no sistemas educacionais do Brasil e de outros países, principalmente os menos desenvolvidos. Esse cenário tem realçado a necessidade de um padrão de qualidade de ensino capaz de propiciar meios adequados para prática dos processos de ensino e aprendizagem. Em face da norma contida no artigo 206, inciso VII, da Constituição Federal de 1988, é consagrado o princípio da garantia de padrão de qualidade do ensino (BRASIL, 1988).

Um padrão de qualidade do ensino é fundamental para o desenvolvimento do grupo social, extensivo à sociedade que, segundo Pena (2019), faz parte das políticas educacionais defendidas pela Unesco e OCDE e também pela Declaração de Bolonha, os quais são órgãos que tratam a educação como elemento crucial para o desenvolvimento econômico social. Daí as diversas políticas voltadas para a melhoria da educação que vêm sendo implementadas a partir do final da década 
de 1990, que visam garantir o direito à educação para todos, com mais qualidade. De acordo com Pena (2019), o período pós-década de 1990 tem sido palco de inúmeras mudanças na área educacional, com exigências que têm levado a recomendações de políticas e programas com um novo padrão para a educação básica, que é obrigatória e está sob tutela dos Direitos Humanos, bem como para a educação superior.

Nesse sentido, é difícil separar direitos humanos de direitos fundamentais porque dentre eles há uma zona cinzenta, resultado dessa intercessão, da qual consta um elemento comum, qual seja, a proteção da pessoa humana e seus direitos elementares, dentre eles o direito à vida, à segurança e à educação. São direito interdisciplinares e que precisam de atenção equânime do Poder Público. Segundo Sarlet (2018, p. 18), a dificuldade de separar esses direitos está no fato de que o termo "direitos fundamentais" se aplica para aqueles direitos do ser humano reconhecidos e confirmados na esfera do Direito Constitucional. A expressão "direitos fundamentais" se aplica para aqueles direitos do ser humano reconhecidos e positivados na esfera do direito constitucional positivo de determinado Estado, e "direitos humanos" tem uma dimensão mais ampla e guarda relação com o Direito Internacional por referir-se a posições jurídicas que reconhecem o ser humano como indivíduo pertencente à ordem mundial, não somente à ordem constitucional do seu país.

\section{Judicialização: concepção e finalidade}

Nos últimos anos, a vida dos brasileiros tem recebido processos judiciais extensos e profundos em todos os campos relevantes, tanto no plano ético e dos costumes, como em matéria econômica e em temas de natureza social, ou seja, segundo Barroso (2018, p. 22-23), uma impressionante judicialização da vida tanto do ponto de vista quantitativo quanto qualitativo. A judicialização quantitativa refere-se a um aumento vultoso de litigiosidade no Brasil, que se expressa por meio da existência de um número espantoso de ações judiciais em curso e judicialização qualitativa implica, segundo o entendimento de Barroso (2018, p. 25), muitas vezes, na transferência significativa de poder das instituições políticas tradicionais - o Legislativo e o Executivo - para o Poder Judiciário.

No entendimento de Barroso (2018, p. 15), "há uma discussão ampla no Brasil sobre judicialização em diversas áreas", e cabe observar que este fenômeno chega também no cenário educacional. Segundo o autor, o momento é importante para se discutir políticas públicas e recursos para a saúde, para a previdência, para o funcionalismo público, para o transporte, para a publicidade institucional, mas principalmente, para a educação. A judicialização demonstra que os direitos e garantias fundamentais estão sendo exercidos pelo indivíduo em sociedade quando recorrem ao 
poder público para fazer valer os seus direitos. A judicialização na área educacional é a demonstração de que o Poder Público está deixando de cumprir, em algum aspecto, o seu papel estatuído da Constituição Federal de 1988, em relação à garantia do direito à educação. A delimitação de atuação do Poder Judiciário é traçada pela legislação, uma condição que define a amplitude da judicialização. Segundo Barroso (2018, p. 24), o modo de atuação do judiciário é o de "autocontenção", o que significa que o Poder Judiciário decidirá dentro dos "limites da lei” quaisquer questões colocadas em pauta de discussão e análise.

\section{A judicialização do direito à educação e seus aspectos fundamentais}

É importante ressaltar que existem várias acepções do termo educação, oferecidas por diferentes autores. Apesar de algumas divergências, na maioria das vezes, têm questões em comum que, notadamente, assentam-se no indivíduo, que é o epicentro dos processos de ensino e de aprendizagem. Considerando a educação no século XXI, não se pode reduzir o sentido da expressão apenas a um aspecto formal, mas ao direito de aprender nessa realidade atual, do mundo globalizado e tecnologizado (CÁRIA; ALVES, 2018, p. 474), em que as "políticas de educação assumiram um olhar voltado para a aprendizagem ao longo da vida”, portanto, uma nova concepção. Para Calleja (2008), a educação é um método de influência sobre as pessoas que conduz à sua transformação e as capacita para interagir com o meio. E essa condução do indivíduo pela educação gera direitos e deveres, consequentemente.

O vocábulo direito, segundo uma síntese de Iribure Júnior (2016, p. 79), “pode ser estudado de acordo com um sentido geral e como técnica", sendo que, no entendimento de Abbagnano (1998, p. 278), o direito é, em sentido amplo e elementar, “[...] a técnica da coexistência humana, isto é, a técnica que visa a possibilitar a coexistência dos homens". Isto é, enquanto técnica, o direito se consolida em conjunto de leis ou normas, que têm por finalidade a ética entre os homens.

Para Iribure Júnior (2016, p. 79), a palavra “direito” pode ser analisada num sentido geral como a técnica de coexistência humana. Como técnica, o Direito se consolida como um conjunto de regras (leis ou normas), que têm por objeto a conduta inter-subjetiva, ou seja, a conduta dos homens entre si (ABBAGNANO, 1998). A Filosofia o coloca entre as derivações da Sociologia, porque não se aceita o Direito sem a existência do homem, vivendo em sociedade, ou seja, em concordância com Silva (2014, p. 1078), “onde quer que haja homens reunidos, pois, há necessariamente o Direito, manifestado seja sob que forma for. Não há direito sem sociedade, nem sociedade sem direito". Assim, o direito na prática em busca da justiça, demonstra que nas conformidades da lei nem tudo que é justo é lícito, assim como nem tudo que lícito é justo. A este respeito, 
Iribure Júnior (2016, p. 81) destaca que nem tudo quanto há no direito é justo, e nem tudo que é considerado justo é de direito.

A educação, como constituinte dos direitos sociais, tem fundamento na dignidade da pessoa humana, quer no aspecto individual ou no âmbito social e, dessa forma, confirma seu aspecto “solidário", conforme Cordeiro e Galindo (2007, p. 125). A questão da solidariedade está inscrita no preceito constitucional da dignidade da pessoa humana, fundamenta o Estado Democrático de Direito que, por sua vez, materializa a República Federativa do Brasil (BRASIL, 1988) no texto magno expresso no art. $1^{\circ}$, inciso III, com o objetivo de construir uma sociedade livre, justa e solidária (BRASIL, 1988, art. $3^{\circ}$, inciso I).

Os direitos sociais preditos na atual CF, abarcados como garantias adquiridas ao longo do tempo e da história, nem sempre foram inseridos nas Cartas Magnas anteriores, diga-se na sua extensão atual, ao contrário, são construídos por regras e princípios expressos na Constituição. As estruturas para solidificação do direito à educação constam dos parágrafos $1^{\circ}, 2^{\circ}$ e $3^{\circ}$ do artigo 208 da Constituição Federal de 1988, cuja norma diz que acesso ao ensino obrigatório e gratuito é direito público subjetivo, e o não-oferecimento do ensino obrigatório pelo Poder Público, ou sua oferta irregular, importa responsabilidade pela autoridade competente. Deste modo, compete ao Poder Público recensear os educandos no ensino fundamental, fazer-lhes a chamada e zelar, junto aos pais ou responsáveis, pela frequência à escola.

A judicialização reconhece a possibilidade de qualquer pessoa, física ou jurídica, de ingressar em juízo para discutir um direito ou pretensão (BARROSO, 2018, p. 24). Trata-se de um instituto previsto na Constituição Federal (BRASIL, 1988), no artigo 5º inciso XXXV, bem como no artigo $3^{\circ}$, do Código de Processo Civil Brasileiro (BRASIL, 2015), que diz: "a lei não excluirá da apreciação do Poder Judiciário lesão ou ameaça a direito". Essa apreciação obedece ao princípio da inafastabilidade da jurisdição, ou seja, qualquer situação que demonstre haver lesão ou ameaça a direito deve ser debatida em juízo e decidida pelo Poder Judiciário. Esse princípio fundamental garante às pessoas o direito de ter acesso ao Poder Judiciário para obter uma decisão capaz de dirimir um conflito de interesses (ALVIM, 2019, p. 189). É uma condição na qual “dirige-se diretamente ao legislador, que não pode pretender, por meio de lei, delimitar o âmbito de atividade do Poder Judiciário" (TAVARES, 2020, p. 498). Assim, fica estabelecida a atividade do Poder Judiciário como ente garantidor da estabilidade jurídico-social.

A despeito do direito público subjetivo, o princípio fundamental para a estrutura do direito à educação aponta que é dever do Estado atender a todos os maiores de sete anos no cumprimento dos anos da escolaridade obrigatória, na interpretação de Cury (2002). No Brasil, a Constituição Federal atribui ao Ministério Público à defesa "da ordem jurídica, do regime democrático e dos 
interesses sociais e individuais indisponíveis (art. 127), promovendo as medidas necessárias à sua garantia" (art.129).

Com base nesses exemplos, pode-se notar que a atividade do Poder Judiciário no âmbito das políticas públicas, notadamente no campo dos tribunais superiores, vive uma situação de recrudescimento dos debates em vários espaços sociais nos últimos anos. A vida brasileira foi acometida por um processo de judicialização em vários setores da sociedade, tanto no plano político, ético e dos costumes, como em matéria econômica e em temas de natureza social (BARROSO, 2018, p. 21). Decisões relevantes pertinentes às questões relacionadas às políticas públicas vêm sendo aplicadas com certo rigor no âmbito dos poderes Executivo e Legislativo. São decisões que demonstram que o papel assumido pelo Poder Judiciário não foge do contexto democrático insculpido na Constituição Federal de 1988.

\section{Metodologia}

Os critérios de inclusão, bem como o percentual de aceitabilidade de cada critério, respectivamente, destes trabalhos de pesquisa foram: I.1 (Trabalhos com resumo), correspondente a todos os trabalhos de pesquisa analisados, isto é, uma proporção de 100\%; I.2 (Trabalhos publicados e disponíveis integralmente em bases de dados científicas digitais), correspondente a todos os trabalhos de pesquisa analisados, isto é, uma proporção de 100\%; I.3 (Trabalhos publicados de 19882018), correspondente a todos os trabalhos de pesquisa analisados, isto é, uma proporção de 100\%; I.4 (Trabalhos publicados em periódicos com qualificação Qualis-Capes, trabalhos de pesquisa de discussão em encontros ou congressos de educação, teses e dissertações, dispostos nas fontes listadas na seção "lista das fontes de pesquisa"), correspondente a todos os trabalhos de pesquisa analisados, isto é, uma proporção de 100\%; I.5 (Trabalhos dentro do escopo de pesquisa), correspondente a todos os trabalhos de pesquisa analisados, isto é, uma proporção de 100\%; I.6 (Trabalhos que tratem de direito à educação), correspondente a todos os trabalhos de pesquisa analisados, isto é, uma proporção de $100 \%$. As ideias principais dos dois trabalhos selecionados são apresentadas a seguir:

Uma vez de posse dos dados obtidos na RS, somados às informações teóricas pertinentes, procedeu-se à análise descritiva e à discussão de dados, de forma articulada com atos normativos e constitucionais pertinentes, decisões judiciais advindas do Poder Público no que se refere a qualquer fator relacionado ao direito à educação. 


\section{Resultado da revisão sistemática com o tema "judicialização do direito à educação"}

$\mathrm{Na}$ RS, realizada com o objetivo de levantar as pesquisas sobre o tema judicialização do direito à educação, 59 (cinquenta e nove) trabalhos foram selecionados, mas apenas 2 (dois) trabalhos de pesquisa foram para a última etapa, nos termos do protocolo da RS, efetivamente selecionados e aceitos para compor a formulação dos resultados, o que significa que atenderam aos objetivos da pesquisa, em obediência aos critérios determinados para seleção e análise, sem qualquer dos critérios de exclusão:

Trabalho 1: tema - o novo cenário jurisprudencial do direito à educação no Brasil: o ensino domiciliar e casos no Supremo Tribunal Federal.

O trabalho de pesquisa realizado por Nina Stocco Ranieri (2017), publicado na revista ProPosições, traz um tema relevante para uma nova tendência na educação, que é o Homeschooling. O trabalho que atendeu a todos os critérios de admissibilidade de inclusão estabelecidos no protocolo da RS. Como resultado, a autora apresentou o reconhecimento do STF quanto à constitucionalidade do ensino familiar e religioso confessional em escolas públicas, o que pode marcar uma virada na jurisprudência educacional, elevando-a a uma proteção mais complexa do direito à educação. Se antes de 2015 a decisão do tribunal voltava-se para resolver questões relacionadas ao acesso à educação básica, a partir desses casos, o STF foi provocado para se manifestar sobre os direitos instrumentais relacionados à liberdade de educação, e manifestar-se sobre os limites da autonomia privada e do Estado quanto à educação obrigatória.

Com relação à educação religiosa, o objetivo é impedir que o Estado se comprometa em fornecer essa educação nas escolas públicas; na educação familiar, o objetivo é garantir que ela seja fornecida pela família, sem exigir que os alunos frequentem escolas públicas ou privadas. $\mathrm{O}$ argumento contra o ensino religioso nas escolas públicas é baseado nos princípios do laicidade, nos termos do art. 19, inciso I, da Constituição Federal (1988).

Este estudo também apresenta as normas internacionais, a Constituição Federal (BRASIL, 1988) e a Lei de Diretrizes e Bases da Educação Nacional - LDBEN (BRASIL, 1996) que adjudicaram ao direito à educação atributos jurídicos que as diferenciam em relação aos demais direitos fundamentais.

Ranieri (2017, p. 147) considera o direito à educação como "gênero" a partir do qual os demais direitos educacionais são desenvolvimentos. Desse modo, o direito à educação (gênero) é, basicamente, um direito de promoção e proteção realizado mediante ações estatais positivas. Agora, os direitos na educação (os desdobramentos) têm a função primeira de defesa das liberdades no campo da educação, tais como a liberdade de aprender, ensinar, pesquisar e divulgar o pensamento, 
a arte e o saber; o pluralismo de ideias e de concepções pedagógicas, e a coexistência de instituições públicas e privadas de ensino. A gestão democrática do ensino público; o ensino religioso facultativo; a autonomia universitária.

Em vista deste posicionamento, este trabalho de pesquisa verificou se tais casos já haviam sido julgados. Então, foi verificado que a primeira ação, ADI 4.439, teve seu julgamento concluído em 27 de setembro de 2017. Em sessão plenária realizada nessa data, o STF julgou improcedente a Ação Direta de Inconstitucionalidade (ADI) 4439, na qual a Procuradoria-Geral da República (PGR) questionava o modelo de ensino religioso nas escolas da rede pública de ensino do país. Logo, por maioria dos votos $(6 \times 5)$, os ministros entenderam que o ensino religioso nas escolas públicas brasileiras pode ter natureza confessional, ou seja, vinculado às diversas religiões (BRASIL, 2017, p. 1).

Com relação ao ensino domiciliar, Recurso Extraordinário n. ${ }^{\circ} 888.815$, teve seu julgamento em 12 de setembro de 2018. Em sessão plenária o relator, Ministro Alexandre de Moraes, negou provimento ao recurso extraordinário, com a fixação da seguinte tese: "Não existe direito público subjetivo do aluno ou de sua família ao ensino domiciliar, inexistente na legislação brasileira" (BRASIL, 2018, p. 16). No entendimento do STF (BRASIL, 2018, p. 15-16), a Constituição Federal não veda de forma absoluta o ensino domiciliar, mas proíbe qualquer de suas espécies que não respeite o dever de solidariedade entre a família e o Estado como núcleo principal à formação educacional das crianças, jovens e adolescentes. São inconstitucionais, portanto, as espécies de unschooling radical (desescolarização radical), unschooling moderado (desescolarização moderada) e homeschooling puro, em qualquer de suas variações.

Desse modo, o ensino domiciliar não é um direito público subjetivo do aluno ou de sua família, porém não é vedada constitucionalmente sua criação por meio de lei federal, editada pelo Congresso Nacional, na modalidade "utilitarista" ou "por conveniência circunstancial", desde que se cumpra a obrigatoriedade, de 4 a 17 anos, e se respeite o dever solidário Família/Estado, o núcleo básico de matérias acadêmicas, a supervisão, avaliação e fiscalização pelo Poder Público; bem como as demais previsões impostas diretamente pelo texto constitucional, inclusive no tocante às finalidades e objetivos do ensino; em especial, evitar a evasão escolar e garantir a socialização do indivíduo, por meio de ampla convivência familiar e comunitária, nos termos do art. 227 da Constituição Federal de 1988. 


\section{Trabalho 2: tema - o Supremo Tribunal Federal e a garantia do direito à educação}

Esse trabalho, selecionado pela RS, de autoria de Elisângela Alves da Silva Scaff e Isabela Rahal de Rezende Pinto se encontra publicado na Revista Brasileira de Educação, de São Paulo, Brasil, volume 21, número 65, nas páginas 431-454, de junho de 2016.

Neste trabalho de pesquisa, as autoras investigaram e analisaram a atuação do Poder Judiciário, em particular o STF, no qual usou de demandas judiciais no campo do direito à educação de crianças e adolescentes no período de 2003 a 2012. Por meio da referida análise, as autoras observaram que o STF tem adotado uma postura favorável à efetivação do direito à educação, para a qual tem declarado unanimemente que a educação, em todos os níveis, é direito fundamental social imediatamente exigível do Estado de maneira lato sensu (em sentido amplo) por meio de via judicial, isto é, da judicialização. Scaff e Pinto (2016, p. 2) observaram que, não obstante a importância da posição jurisprudencial assumida pelo STF, existe falta de diálogo da Corte com a área educacional, bem como o tratamento pouco aprofundado dado ao tema.

Não obstante a importância da posição jurisprudencial assumida pelo STF, também observou-se a falta de diálogo da Corte com a área educacional, bem como o tratamento pouco aprofundado dado ao tema. O desempenho das instituições judiciais brasileiras no campo das políticas públicas, especialmente no contexto do STF, nunca foi tão debatido em diferentes campos sociais nos últimos anos. As decisões importantes relacionadas ao assunto geralmente envolvem questões analisadas e determinadas nos ramos executivo e legislativo, e exibe o novo papel do judiciário, a exemplo da "judicialização política".

Scaff e Pinto (2016, p. 434), após discorrerem com brevidade sobre o tratamento da educação pela Constituição Federal de 1988, trazem à tona uma discussão pertinente: o judiciário condena os poderes públicos para proporcionar benefícios materiais a indivíduos ou comunidades, principalmente no que diz respeito à implementação de políticas públicas e seu escopo coletivo. É importante lembrar que, ao mesmo tempo em que os movimentos para afirmar os direitos sociais e a construção de um estado de bem-estar são consolidados na CF de 1988, o país também implementou uma política de controle dos gastos com recursos públicos.

Versa, nesse sentido, considerar a educação como um verdadeiro direito público subjetivo. Este conceito é de grande importância no campo judicial e refere-se a termos técnicos legais construídos no contexto de um Estado liberal burguês e firma direitos individuais, bem como permite que os indivíduos exerçam seus direitos. A maneira de fazê-lo é acionando as normas jurídicas (direito objetivo) e transformando-as em seu direito (direito subjetivo)" (DUARTE, 2004, p. 113).

Em seu trabalho, Scaff e Pinto (2016) excluíram as decisões referentes ao ensino superior, aos direitos trabalhistas, a questões tributárias (especificamente relativas ao salário-educação e à 
imunidade tributária de instituições educacionais), a questões previdenciárias e a questões penais. Após a seleção e leitura integral dos acórdãos, as decisões foram organizadas em um quadro pelo critério da pertinência temática. A análise dos acórdãos foi realizada minuciosamente, caso por caso, sendo posteriormente agrupada para melhor exposição no texto, tendo como destaque a argumentação desenvolvida pelos ministros e o resultado das ações e recursos selecionados.

De acordo com Scaff e Pinto (2016, p. 439), a análise foi conduzida fundamentando-se na ordem normativa e na produção bibliográfica jurídica e educacional existentes sobre as temáticas expostas nas decisões judiciais, que foram classificadas e organizadas por pertinência temática em categorias. Do conjunto de acórdãos analisados, observou-se que a temática presente no STF em relação ao direito à educação refere-se às demandas por acesso a vagas na educação infantil, representativas de $20 \%$ das ações analisadas. Em seguida, estão os acórdãos referentes ao conflito entre os poderes Legislativo e Executivo na elaboração de normas para a educação, com 6 ações analisadas (cerca de 17\%); às ações relativas à contratação temporária de profissionais da educação pública, com 5 acórdãos (cerca de 14\%); os acórdãos referentes ao conflito entre União e os estados membros na elaboração legislativa na temática educacional, com 4 acórdãos (cerca de 11,5\%); as ações alusivas à responsabilidade estatal na garantia ampla do direito à educação e as relativas ao financiamento educacional, ambas com 3 acórdãos cada (cerca de 8,5\%) e os acórdãos relativos ao poder de regulação do Estado em relação aos estabelecimentos privados de ensino, com 2 decisões (cerca de 5,5\%).

As demais temáticas estão representadas por apenas um acórdão, sendo elas: manutenção de turma do ensino fundamental na modalidade Educação de Jovens e Adultos (EJA); escolha de dirigentes de estabelecimentos de ensino mediante eleições diretas; constitucionalidade da meiaentrada; omissão do presidente da República em relação à erradicação do analfabetismo no país e à implementação do ensino fundamental para todos e a constitucionalidade do piso salarial profissional para os profissionais do magistério público da educação básica (SCAFF; PINTO, 2016, p. 440).

Em considerações finais, Scaff e Pinto (2016, p. 449-451) entenderam que o STF, como órgão de cúpula do Poder Judiciário e como Tribunal Constitucional, tem sido solicitado a decidir sobre diversas questões acerca do direito à educação de crianças e adolescentes nos últimos dez anos. Se inicialmente a temática educacional configurou-se como assunto marginal no STF, constata-se que de 1988 até o início de 2013 foram julgados pela suprema corte cerca de 4.410 processos sobre a temática, dos quais 4.222 foram protocolados a partir de 2001. 


\section{Considerações finais}

Observou-se nesse estudo que o tema "judicialização do direito à educação" é recorrente no cenário educacional, e poucas pesquisas desenvolvidas no Brasil tratam de decisões judiciais. Conforme demonstrado ao longo deste texto, pode-se admitir que a judicialização do direito à educação existe porque há má gestão pública dos recursos destinados à educação, não obstante a existência de legislação pertinente que reconhece a educação como bem público e direito subjetivo do cidadão.

O direito público subjetivo consiste em instituto que põe o seu titular em conjuntura provida de algumas faculdades jurídicas que são garantidas pelas normas de organização social e, daí, extrai-se a importância de políticas públicas que possam garantir a efetivação dos direitos fundamentais, dentre eles a educação, por ser um atributo da pessoa, conforme Declaração Universal dos Direitos Humanos e reconhecidos pela CF no Estado brasileiro.

A judicialização ocorre porque verificam-se situações jurídicas em que o Poder Público tem obrigações, ou seja, o dever de dar, fazer ou não fazer algo em benefício de um indivíduo interessado. Cabe destacar a necessidade de o judiciário se esforçar para acompanhar a evolução da educação no Brasil e no mundo, a fim de tomar decisões coerentes e alinhadas com a dinâmica social, posto que é deste movimento interno na sociedade que surgem novas necessidades didático-pedagógicas, novas ferramentas de ensino-aprendizagem e, com elas, direitos e deveres, que, por sua vez, podem vir a suscitar conflitos a serem dirimidos nos tribunais. Daí se interpreta juridicamente que todo direito tem um objeto; é uma prestação de contrapartida do que se supõe um comportamento ativo ou omissivo por parte do devedor, neste caso, o Poder Público. Cabe ao Ministério Público levar ao Judiciário situações que entende prejudiciais ou que ferem os direitos sociais, no caso, relacionados ao direito à educação.

\section{Referências}

ABBAGNANO, Nicola. Dicionário de filosofia. São Paulo: Martins Fontes, 1998.

ALVIM, Arruda. Manual de direito processual civil. 18. ed. São Paulo, Brasil: Revista dos Tribunais, 2019.

BARROSO, Luis Roberto. A judicialização da vida e o papel do Supremo Tribunal Federal. Belo Horizonte: Fórum, 2018.

BIOLCHINI, Jorge Calmon de Almeida et al. Scientific research ontology to support systematic review in software engineering. Advanced Engineering Informatics, v. 21, n. 2, p. 133-151, 2007.

BRASIL. Lei n. 9.394, de 20 de dezembro de 1996. Estabelece as diretrizes e bases da educação nacional. Diário Oficial da União, Brasília, DF, Presidência da República, 23 dez. 1996. 
BRASIL. Lei 13.105, de 16 março 2015. Institui o Código de Processo Civil Brasileiro. Diário Oficial da União, Brasília, DF, Poder Executivo, 17 mar 2015.

BRASIL, [Constituição (1988)]. Constituição da República Federativa do Brasil. Diário Oficial da União, Brasilia, DF, Congresso Nacional, 05 out. 1988.

BRASIL, STF. STF conclui julgamento sobre ensino religioso nas escolas públicas. Disponível em: http://www.stf.jus.br/portal/cms/verNoticiaDetalhe.asp?idConteudo=357099. Acesso em: 25 jul. 2020.

BRASIL, STF. Decisão Plenária. Recurso Extraordinário n. ${ }^{\circ}$ 888.815. Relator: Min. Alexandre de Moraes. Diário da Justiça Eletrônico, 2018.

BRASIL, Tribunal de Contas da União. 8 objetivos estratégicos e indicadores de desempenho 1. Brasília: [s.n.]. Disponível em: http://portal2.tcu.gov.br/. Acesso em: 12 jul. 2020.

BRASIL, Tribunal de Contas da União. Educação | Portal TCU. Disponível em: https://portal.tcu.gov.br/educacao/. Acesso em: 12 jul. 2020.

CALLEJA, José Manuel Ruiz. Os professores deste século. Rev. Inst. Univ. Tecn. del Chocó, v. 27, n. 1, p. 109-117, 2008.

CNJ, Conselho Nacional de Justiça. Justiça em números 2018: ano-base 2017. Brasília: CNJ, 2018.

CÁRIA, Neide P.; ALVES, Juliana C. Pereira. Aspectos de uma epistemologia da educação ao longo da vida: uma nova ordem educativa. Rev. Unisul, Tubarão, v.12, n. 22 p. 471-488, Jun/Dez. 2018 .

CURY, Carlos Roberto Jamil. A Constituição de Weimar. Educação \& Sociedade, v. 19, p. 83-104, 1998.

DUARTE, Clarice Seixas. Direito Público Subjetivo e Políticas Educacionais. Revista São Paulo em Perspectiva, v. 18, n. 2, p. 113-118, 2004.

FAVARO, Neide de Almeida Lança Galvão; TUMOLO, Paulo Sergio. A relação entre educação e desenvolvimento econômico no capitalismo. Educação \& Sociedade, v. 37, n. 135, p. 557-571, jun. 2016.

IRIBURE JÚNIOR, Hamilton da Cunha. Direito à educação. Direito e Desenvolvimento, v. 7, n. 2, p. 77-95, 2016.

KITCHENHAM, Barbara. Procedures for Performing Systematic Reviews. Newcastle-under-Lyme, UK: Keele University Technical Report TR/SE-0401, 2004. Disponível em: http://www.inf.ufsc.br/ aldo.vw/kitchenham.pdf.

PENA, Neide. As competências para ensinar e a profissionalização da docência. In: SANTOS, Samuel Carvalho Dos; PENA, Neide. Docência Universitária: o desafio de reinventar a sala de aula. Campinas: Pontes Editores, 2019. p. 87-139.

RANIERI, Nina Beatriz Stocco. O novo cenário jurisprudencial do direito à educação no Brasil. Pro-Posições, v. 28, n. 2 (83), p. 141-171, 2017. 
SCAFF, Elisângela Alves da Silva; PINTO, Isabela Rahal de Rezende. O Supremo Tribunal Federal e a garantia do direito à educação. Revista Brasileira de Educação, v. 21, n. 65, p. 431-454, jun. 2016.

SILVA, De Plácido e. Dicionário jurídico. 31. ed. São Paulo: Forense, 2014.

TAVARES, André Ramos. Curso de Direito Constitucional. 18. ed. São Paulo, Brasil: Saraiva JUR, 2020. 